\title{
The Effect of Soil Volume on Young Peach Tree Growth and Water Use
}

\author{
A-M. Boland ${ }^{1}$, P.D. Mitchell' ${ }^{2}$, I. Goodwin' ${ }^{1}$, and P.H. Jerie ${ }^{3}$ \\ Institute of Sustainable Irrigated Agriculture, Tatura Centre, Department of Agriculture Victoria, Private \\ Bag, Tatura 3616, Australia
}

Additional index words. Prunus persica, root volume restriction

\begin{abstract}
An experiment designed to study the effects of different root volumes was installed in Fall 1991. 'Golden Queen' peach trees [Prunus persica $(\mathbf{L}$.$) Batsch.] were planted into different isolated soil volumes (0.025,0.06,0.15,0.4$, and 1.0 $\mathrm{m}^{3}$ ), which were essentially individual drainage lysimeters. Trunk cross-sectional area (TCA) increased from 5.76 to 14.23 $\mathrm{cm}^{2}$ for the smallest and largest volumes, respectively, while leaf area was 4.56 and $21.32 \mathrm{~m}^{2}$ for the respective treatments. Leaf size was not affected by soil volume. Soil volume was positively related to the number of lateral shoots produced, lateral shoot density, and internode length. Total flower bud number and flower bud density were inversely related to soil volume. Fruit set was similar among treatments despite an almost 4-fold difference in tree size. Tree water use (liters $\cdot \mathbf{m m}^{-1}$ pan evaporation) increased with soil volume; however, when adjusted for tree size (tree water use per TCA), there were no consistent differences between treatments for tree water use over the season. These results suggest that trees planted in the smaller soil volumes were more efficient reproductively per unit of tree size and would be easier to manage in an ultra-high-density planting.
\end{abstract}

Controlling tree vigor and size without sacrificing yield potential limits the success of high-density plantings (Purohit, 1989). Several options have been identified to control vegetative vigor in deciduous orchards (Jerie et al., 1989); however, not all of these options are applicable to peach or are economically viable. For example, suitable dwarfing rootstocks are not available for peach, and summer pruning and growth regulators can be costly and produce adverse side effects.

Peach tree vigor is related to the volume of soil available to the root system (Cockcroft and Wallbrink, 1966b) and, for a particular environment, the relative growth rate of the root system limits the potential for vegetative growth (Chalmers, 1988). This relationship between roots and shoots has been researched in detail by Richards and Rowe (1977a, 1977b) and Richards (1977, 1986). They determined that limiting root development can effectively reduce vegetative vigor.

Root restriction can be achieved by natural (Cockcroft and Wallbrink, 1966a, 1966b) or artificial barriers in the soil (Williamson and Coston, 1990; Williamson et al., 1992), root competition from neighboring plants (Chalmers et al., 1981), or controlling the spread and penetration of irrigation water (Richards and Cockcroft, 1975). Artificial root barriers have controlled vegetative growth of peach in humid regions with abundant spring rains and deep fertile soil (Williamson and Coston, 1990).

Irrigation management also controls vigor. Regulated deficit irrigation (RDI) is designed to control excessive vegetative vigor by reducing irrigation during rapid vegetative growth. Orchard productivity has been improved under RDI by increased yields, easier management, and improved water use efficiency (Chalmers et al., 1981, 1986; Mitchell and Chalmers, 1982; Mitchell et al., 1984, 1986, 1989; Proebsting, 1990). However, while RDI is

Received for publication 8 Dec. 1993. Accepted 17 June 1994. This research was supported by the Australian Centre for International Agricultural Research. We thank A.P.L. Callinan, Biometrics Services, Victorian Dept. of Agriculture, for assistance with statistical analysis. The cost of publishing this paper was defrayed in part by the payment of page charges. Under postal regulations, this paper therefore must be hereby marked advertisement solely to indicate this fact.

${ }^{1}$ Irrigation specialist, Horticulture Section.

${ }^{2}$ Retired.

${ }^{3}$ Horticulture Section leader and irrigation specialist. successful under conditions in the Goulburn Valley (Victoria, Australia), its application is not effective worldwide. This could relate to relatively shallow soils of the Goulburn Valley region, which restrict root volume (Richards and Rowe, 1977b) and allow moderate levels of water stress (Garnier and Berger, 1985).

Recognizing the effects of root restriction and volume, Williamson and Coston (1990) advocated future research on determining the appropriate root volume needed to achieve the desired suppression of vigor for a species. We aimed to determine the optimum root volume by studying growth and reproductive parameters of peach growing in five different soil volumes ranging from 0.025 to $1.0 \mathrm{~m}^{3}$, in which roots were artificially restricted.

The work reported in this paper relates to the effect of soil volume on peach growth and water use in the first year.

\section{Materials and Methods}

Experimental layout and construction. The experiment was designed as a $10 \times 4$ randomized complete block, consisting of four rows of trees each representing a replication. Each plot comprised four trees - the two middle experimental trees and two outer guard trees. There were ten treatments in each row consisting of five different soil volumes (Table 1) split for presence or absence of RDI. In the first year, irrigation treatments were not imposed, allowing eight replicates of each of the five soil volumes.

The experiment was installed in Fall 1991. 'Golden Queen' peach trees were planted in late winter. Each tree was planted into an isolated volume of soil-essentially an individual lysimeter. Holes were dug at the predetermined dimensions (Table 1) and lined with plastic. Drainage pipes were installed and connected to a drainage sump.

Table 1. Description of treatments—-soil volumes and dimensions.

\begin{tabular}{lcccc}
\hline \hline Treatment & $\begin{array}{c}\text { Total vol } \\
\left(\mathrm{m}^{3}\right)\end{array}$ & $\begin{array}{c}\text { Length } \\
(\mathrm{cm})\end{array}$ & $\begin{array}{c}\text { Width } \\
(\mathrm{cm})\end{array}$ & $\begin{array}{c}\text { Depth } \\
(\mathrm{cm})\end{array}$ \\
\hline 1 and 2 & 0.025 & 25 & 25 & 40 \\
3 and 4 & 0.06 & 30 & 50 & 40 \\
5 and 6 & 0.15 & 60 & 60 & 40 \\
7 and 8 & 0.40 & 100 & 100 & 40 \\
9 and 10 & 1.00 & 100 & 120 & 80 \\
\hline
\end{tabular}


A Shepparton fine sandy loam topsoil (Skene and Poutsma, 1962) fertilized with superphosphate and top-dressed with lime and gypsum was then backfilled into each lysimeter to give the desired volume.

Orchard and irrigation management. Trees were planted in a high-density orchard (1-m in-row and 4-m between-row spacings) and trained to the V-shaped mini-Tatura trellis (van den Ende and Chalmers, 1982; van den Ende et al., 1987). All trees were irrigated to maintain maximum growth, with no RDI treatment imposed during the first year. Trees were fertigated weekly with calcium nitrate, and normal orchard management practices were followed. The trees in the larger soil volume had reached $2 \mathrm{~m}$ height by the end of the season.

Irrigation was based on estimated water use per unit of tree size (Black et al., 1977) using $\approx 0.3$ liters per millimeter U.S. Class A pan evaporation (E) per square centimeter trunk cross-sectional area (TCA). Estimated tree water use and a volumetric water content of $10 \%$ in each soil volume (readily available water between 0.004 and $0.08 \mathrm{MPa}$ ) determined irrigation interval. For instance, the smallest soil volume treatment ( 25 liters) held $\approx 2.5$ liters of readily available water. If the TCA of trees planted in this volume was $4 \mathrm{~cm}^{2}$, on a day with $4 \mathrm{~mm}$ evaporation, trees would use an estimated 4.8 liters of water and therefore require irrigation twice daily. Tensiometers were used to check irrigation scheduling based on the above calculations.

Growth, reproductive, and water-use measurements. Tree growth was monitored by measuring trunk diameter $15 \mathrm{~cm}$ above the ground. TCA was calculated every second week and seasonal increase was determined.

At the end of the growing season, canopy volume was calculated, assuming each side of the Tatura trellis to be a rectangular prism with depth, width, and length parameters. For each side, depth and width at $1 \mathrm{~m}$ height and length from the middle of the tree crotch to the branch top were measured. Leaves were sampled from a known cube volume $\left(0.008 \mathrm{~m}^{3}\right)$ at six representative sites from each side of the tree. Leaves were counted and total leaf area from the cube samples was determined with a planimeter. Average leaf size, leaf area per unit of canopy volume, and total leaf area per tree were calculated from the cube samples and canopy volume.

Several variables were measured at bud burst (31 July 1992) in the second year. A representative main limb on one side of the tree was selected and tagged for measurement. This branch represented about one-fourth of the total tree canopy, as trees were trained to four main branches. Total lateral shoot length, lateral shoot number, and length of this branch were measured. From these measurements, average lateral shoot length and lateral shoot number per centimeter of branch length were calculated. The number of nodes per $200 \mathrm{~cm}$ of lateral shoot length was counted and average internode distance was calculated.

Total number of flower buds on the sampled branch was counted at bud burst. There was no separation of number of double and triple buds per node. Total flower bud number as a function of lateral shoot length (flower bud density) was calculated. Number of fruit were counted 50 days after full bloom on the branch previously measured. Fruit set as a percentage of total flower bud number was calculated.

Total tree water use (liters) was estimated every second week for each tree from irrigation and drainage measurements. Change in water content in the profile over the fortnight was assumed to be negligible, given the optimal soil moisture conditions. Tree water use was expressed as liters per millimeter E using a Class A pan evaporimeter situated $40 \mathrm{~m}$ from the site. Water use of young trees largely depends on tree size (Black et al., 1977; Mitchell et al., 1991). Therefore, tree water use per TCA was calculated.

Leaf water potentials were measured with a pressure chamber toward the end of the growing season. Measurements were taken on three occasions from 12:00 to 15:00 HR on the $0.025-, 0.15-$, and $1.0-\mathrm{m}^{3}$ soil volumes.

Statistical analysis. Tree growth was modeled with the Mitscherlich or asymptotic regression curve $\left(y=A+B \cdot R^{x}\right)$. Goodness of fit was determined by adjusted $R^{2}$ and the significance of regression coefficients. Those variables for which the asymptotic model was not appropriate were modeled by analysis of variance (ANOVA), with soil volumes fitted as linear and quadratic orthogonal polynomials. Goodness of fit was determined by the significance of the linear and quadratic components and the

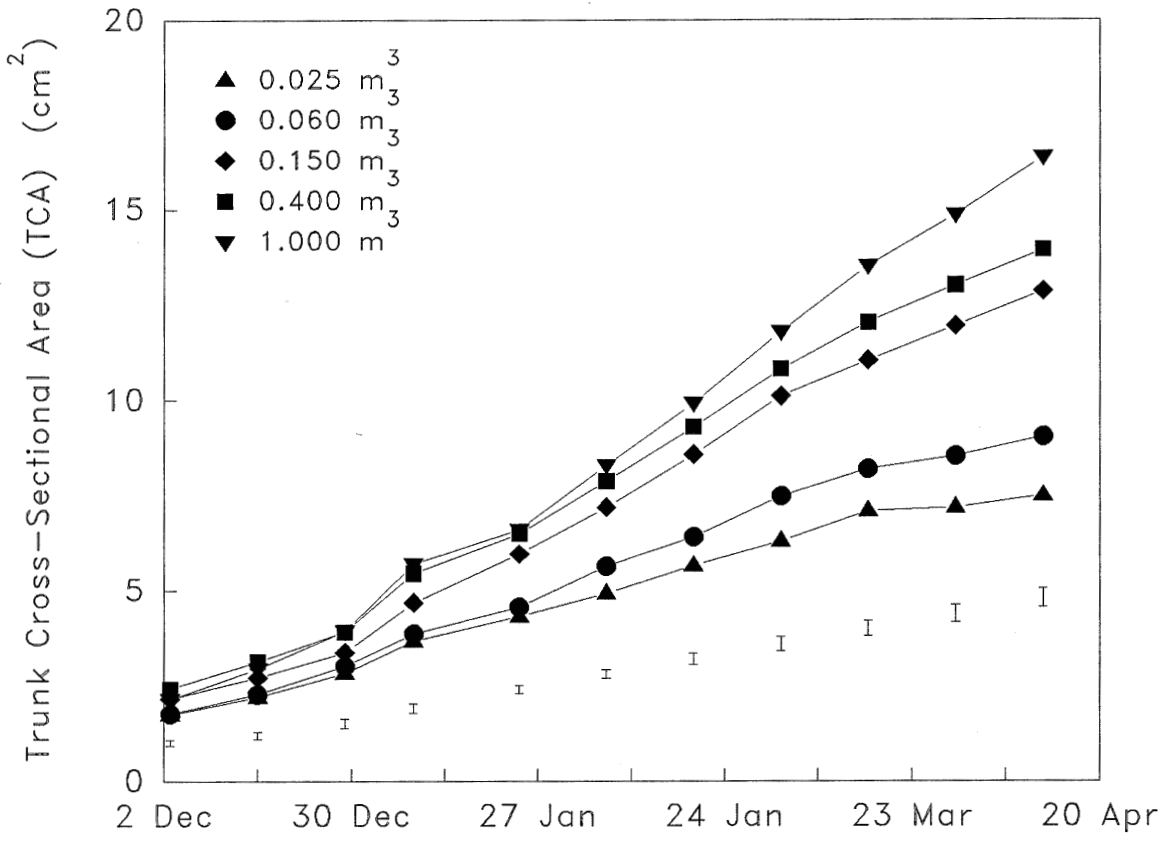

Fig. 1. Effect of soil volume on trunk cross-sectional area increase over the season. Vertical bars are sEDs. 
deviations. For TCA and tree water use over the season, standard errors of the difference were used to compare treatments at each measurement date. Statistical analysis was done with Genstat 5 (Lawes Agricultural Trust, 1990).

\section{Results}

Vegetative growth. Increase in TCA $\left(\mathrm{cm}^{2}\right)$ is a good indicator of tree growth (Westwood and Roberts, 1970), and Fig. 1 illustrates the progressive effect of soil volume on TCA. Soil volume significantly affected TCA beginning at mid-December, and this difference increased to the end of the season. Total TCA increase over the season was $5.76 \mathrm{~cm}^{2}$ for the smallest volume compared with $14.23 \mathrm{~cm}^{2}$ for the largest volume. There was a significant effect of soil volume on TCA increase (Fig. 2a).

Final canopy volume was significantly related to soil volume (Fig. 2b). Maximum values ranged from 0.50 to $1.92 \mathrm{~m}^{3}$ on the smallest and largest volumes, respectively. As a direct result of the difference in canopy volume, calculated leaf area per tree $\left(\mathrm{m}^{2}\right)$ showed a similar significant relationship with soil volume (Fig. 2c). Leaf area ranged from $4.56 \mathrm{~m}^{2}$ on the smallest volume treatment to $21.32 \mathrm{~m}^{2}$ for the largest.
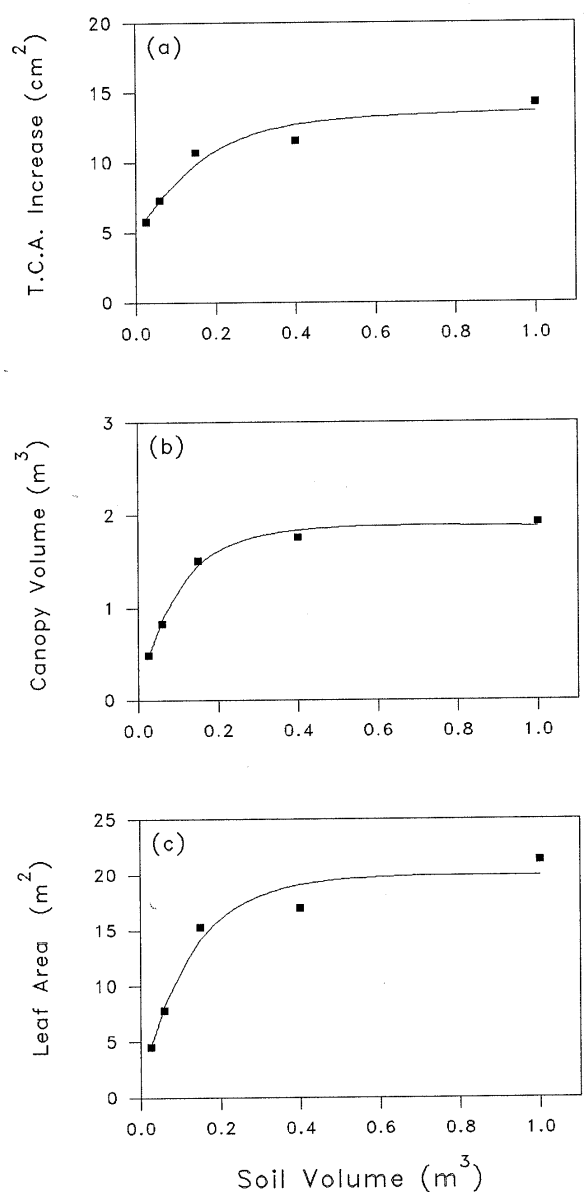

Fig. 2. Modeled (-) and observed ( $\square$ ) effects of soil volume on (a) TCA increase, (b) canopy volume, and (c) leaf area. Model $\left(\mathrm{y}=\mathrm{A}+\mathrm{B} \cdot \mathrm{R}^{\mathrm{x}}\right)$ parameters, where $\mathrm{x}$ is the soil volume (values in brackets are SES):

\begin{tabular}{llll}
$\mathrm{y}$ & $\mathbf{a}$ & $\mathbf{b}$ & \multicolumn{1}{c}{$\mathbf{c}$} \\
$\mathrm{A}$ & $13.64(0.41)$ & $1.88(0.065)$ & $19.91(1.21)$ \\
$\mathrm{B}$ & $-8.80(0.58)$ & $-1.79(0.146)$ & $-18.74(2.24)$ \\
$\mathrm{R}$ & $0.0036(0.0038)$ & $0.00006(0.00011)$ & $0.0036(0.00087)$ \\
$R^{2}$ & 85.9 & 84.6 & 68.7 \\
$\begin{array}{l}\text { Residual } \\
\text { mean square }\end{array}$ & 1.44 & 0.0558 & 16.48
\end{tabular}

Leaf and lateral shoot distribution. Soil volume did not significantly affect leaf size $(P>0.33)$ or calculated leaf area per unit of canopy volume $\left(\mathrm{m}^{2} \cdot \mathrm{m}^{-3}\right)(P>0.37)$.

There was a significant positive linear and negative quadratic effect of soil volume treatment on total lateral shoot length (Fig. 3a). This difference was attributed to lateral shoot number (Fig. 3b) - the effect of soil volume was significant for the linear and quadratic components, while average lateral shoot length was similar between treatments. Lateral shoot density, as measured by
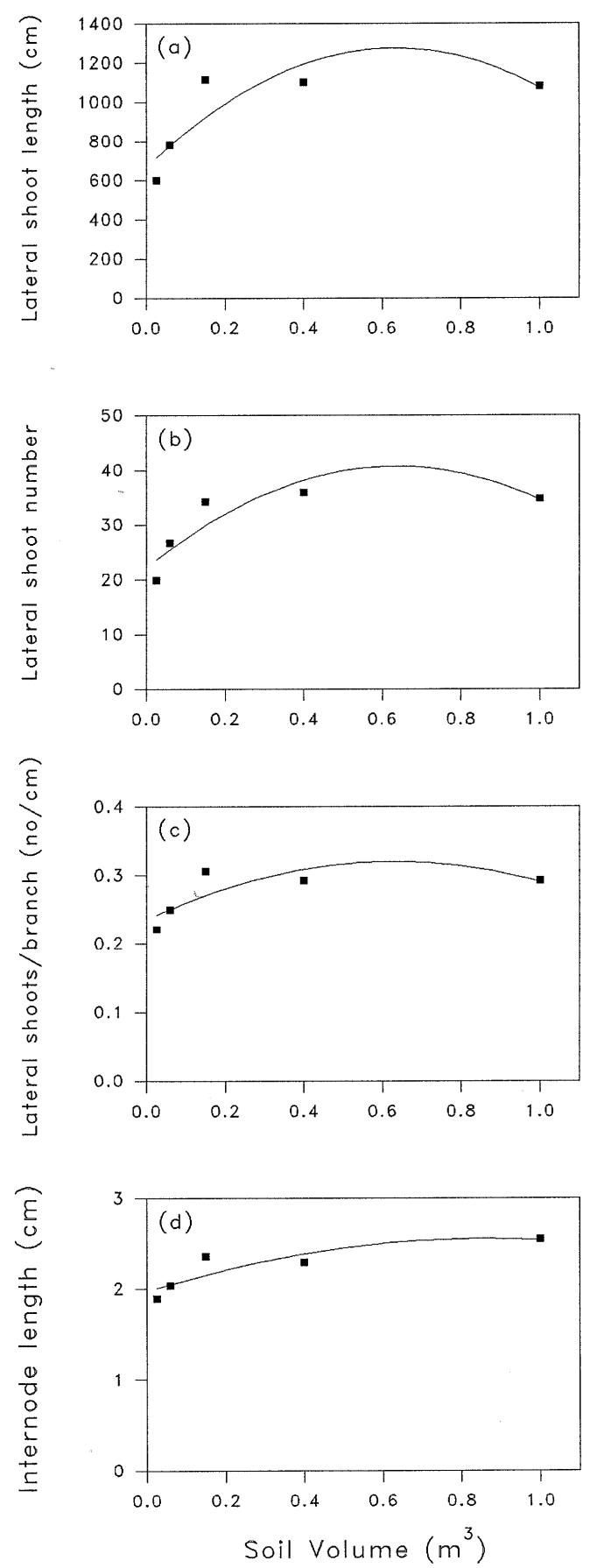

Fig. 3. Modeled (-) and observed ( $\square$ ) effects of soil volume on (a) total lateral shoot length, (b) lateral shoot number, (c) lateral shoot number per unit of branch length, and (d) internode length.

Significance $(P)$ of contrasts

Linear

Quadratic

Residual mean square 
lateral shoot number per unit of branch length, showed trends for soil volume effects (Fig. 3c). This demonstrates that lateral shoot density was greater on the larger soil volume treatments, supporting visual observations (Fig. 4).

Node number per unit of lateral shoot length (node density) was greater on the small volume treatments (results not shown) and calculated internode length was positively related to increasing soil volume (Fig. 3d). As a result of node density and branch size, there was little effect of soil volume on total number of nodes per sampled branch.

Flowering and fruit set. Soil volume had a significant negative effect on flower bud number, showing a greater flower bud number despite less total lateral shoot length on the smaller soil volumes (Fig. 5a). Thus, when adjusted for lateral shoot length (flower bud number per length of lateral shoot), the above differences were accentuated (Fig. 5b).

Soil volume did not affect the total number of fruit produced (Fig. 5c). However, fruit set (percent) increased linearly with increasing soil volume (Fig. 5d).

Tree water use. Total tree water use (liters) increased over the season to harvest and then declined. The volume of water used per tree over 2 weeks reached a maximum of 201.3 and 99.3 liters for the largest and smallest soil volumes respectively.

When related to evaporative demand, tree water use over the season varied with soil volume treatment, and these differences increased over time (Fig. 6a). Maximum tree water use was 3.71 liters $\cdot \mathrm{mm}^{-1} \mathrm{E}$ for the largest and 1.58 liters $\cdot \mathrm{mm}^{-1} \mathrm{E}$ for the smallest soil volume treatment. When averaged over the entire season, tree water use was significantly $(P<0.001$, linear and quadratic) positively related to increasing soil volume. When tree water use was adjusted for tree size (tree water use per TCA), there were no consistent differences between treatments during the season (Fig. 6b). Average tree water use per TCA over the whole season showed no effect of soil volume.

Leaf water potentials did not differ among soil volumes (results not shown), indicating that irrigation strategy did not limit tree water use of the smaller soil volume treatments and that the soil volume effect was not confounded by water stress.

\section{Discussion}

Williamson and Coston (1990) recognized that cultural methods to restrict roots and manipulate plant water status could control vegetative growth. This would be particularly applicable in humid regions with abundant spring rains and fertile soils.

Cockcroft and Wallbrink (1966b) and Richards and Cockcroft (1974) showed a positive relationship between the volume of soil readily accessible to the root system and amount of peach tree vigor.

Trees grown in the smallest volume were smaller for all growth
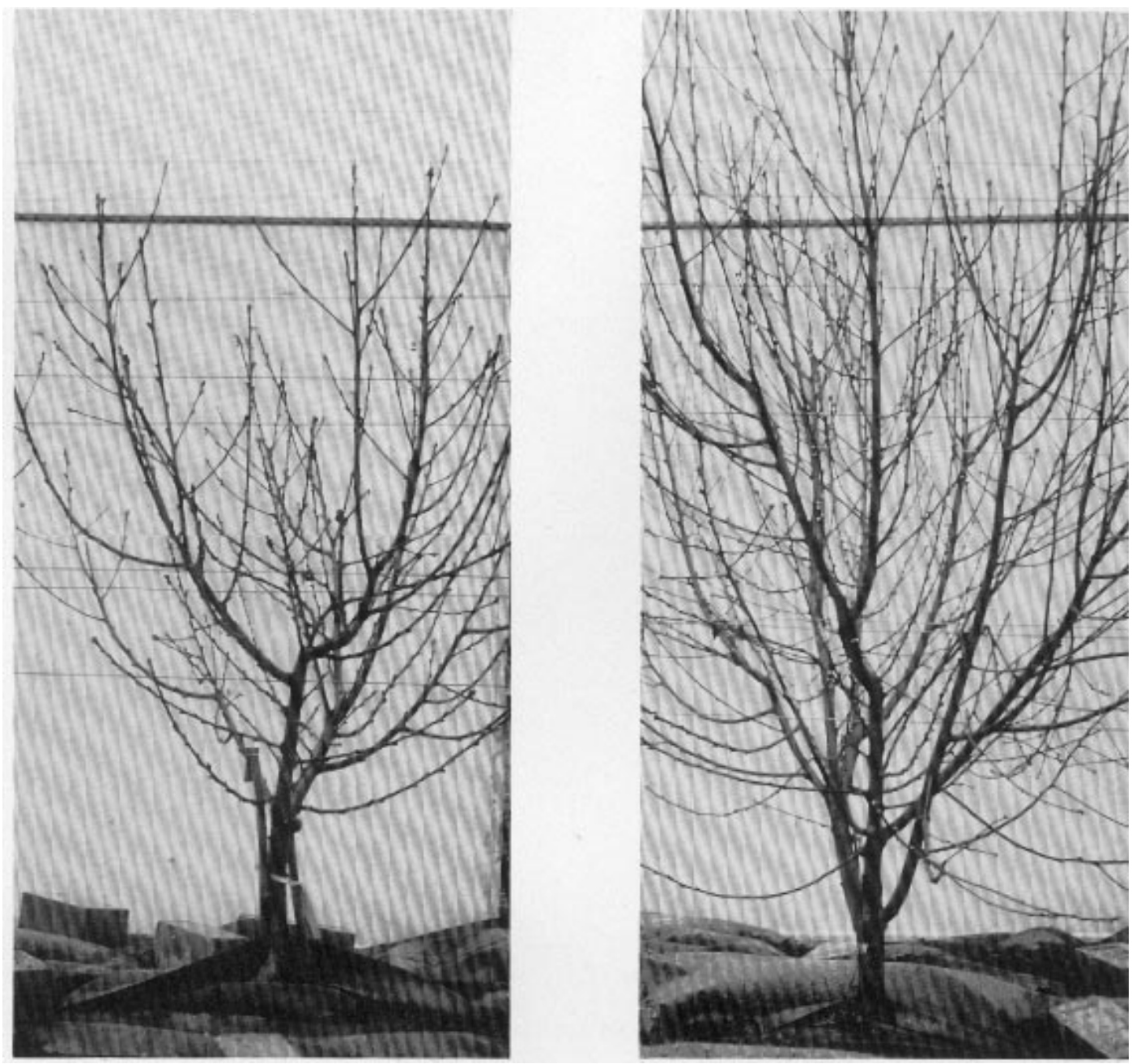

Fig. 4. Lateral distribution of peach trees in the winter following one growing season: (left) tree grown in soil volume of $0.025 \mathrm{~m}^{3}$ (right) tree grown in soil volume of $1.0 \mathrm{~m}^{3}$. 
characteristics measured except leaf size and leaf area per unit of canopy volume. This result was consistent with other experiments in which root restriction limited vegetative growth (Proebsting et al., 1989; Richards, 1981, 1986; Richards and Rowe, 1977a, 1977b; Williamson and Coston, 1990). Seasonal TCA showed
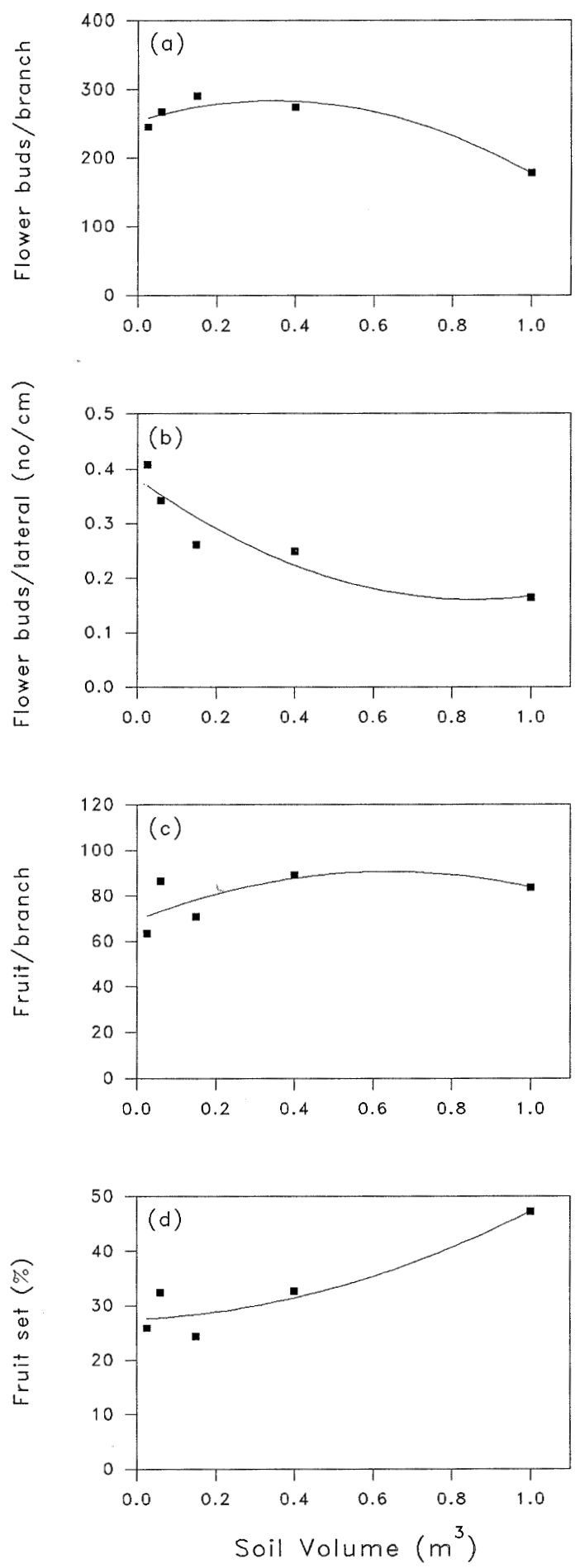

Fig. 5. Modeled (-) and observed ( $\square$ ) effects of soil volume on (a) flower bud number, (b) flower bud number per unit of lateral length, (c) fruit number, and (d) fruit set.

$\begin{array}{lllll}\text { Significance }(P) \text { of contrasts } & \text { a } & \text { b } & \text { c } & \text { d } \\ \text { Linear }(P) & <0.001 & <0.001 & 0.38 & <0.001 \\ \text { Quadratic }(P) & <0.02 & 0.01 & 0.37 & 0.29 \\ \text { Residual mean square } & 3,023 & 0.003 & 980.1 & 94.44\end{array}$

suppression of vegetative growth in the small soil volumes, indicating an almost immediate effect of soil volume on top growth. Furthermore, the divergence in growth midseason of the intermediate from the largest soil volumes may reflect progressive restriction effects occurring at different times depending on soil volume.

Soil volume did not affect leaf size or leaf area per unit of canopy volume. This finding is significant for two reasons. First, Richards and Rowe (1977a, 1977b) hypothesized that total leaf area and leaf size depended on the uptake of water and nutrients. It would therefore appear that nutrient or water uptake were nonlimiting in the first year of the experiment. Second, it is well documented that water stress reduces leaf size (Kramer, 1974) and canopy density (Boland et al., 1993). Maintaining leaf size and measuring leaf water potentials indicate an absence or minimal effect of water stress on growth, suggesting a direct effect of soil volume treatment.

Nodes counted in spring of the second year reflected leaf density in the previous season and showed reduced internode distance and decreased density of lateral shoots on branches of the smaller soil volumes. Hence, the smaller soil volumes had a more open lateral shoot structure with greater leaf density on lateral shoots resulting in similar numbers of leaves per unit of canopy volume.

Although mean lateral shoot length was similar, total lateral shoot length decreased with reduced volume - a result of shorter branch length and reduced lateral shoot density.

Unlike Williamson et al. (1992), we did not differentiate primary and secondary lateral shoots. However, it is proposed that the greater lateral shoot number per unit of branch length on the larger volumes resulted from a higher proportion of smaller, secondary lateral shoots. This resulted in similar mean lateral shoot lengths of all soil volumes and would also support the findings of Williamson et al. (1992). Restricting soil volume reduced the number of lateral shoots produced most likely due to a reduced production of secondary lateral shoots. The resultant small open tree with a predominance of strong primary lateral shoots and high leaf density would seem an ideal unit for a high-density planting, requiring less pruning and favoring quality fruit.

Our results of increased flower bud densities for small soil volumes are consistent with those of Williamson and Coston (1990) and highlight the dramatic effect of root volume on fruitfulness. Williamson et al. (1992) attributed the differences in flower bud density primarily to a greater number of flowers per node. While number of flowers per node were not counted in our experiment, increased flower-bud densities were in part a function of decreased internode length. Williamson and Coston (1990) proposed that enhanced flower bud development may be under hormonal control; however, we did not determine or measure the many hormones that may have influenced growth and development. Differences in tree growth and development under different soil volumes were nevertheless consistent with growth effects often attributed to changes in plant hormone status rather than plant water relations. Alternatively, increased flowering may have been a result of the level of vigor control achieved under the smaller soil volumes (Proebsting et al., 1989, Williamson et al., 1992).

Total number of fruit per tree was not affected by soil volume despite the effect on tree size, a result that may have important implications for future productivity.

Tree water use over the season declined with soil volume. Proebsting et al. (1989) also showed a decrease in water use for restricted root volume. After accounting for tree size, there was little difference in water use, indicating that uptake per unit of root 

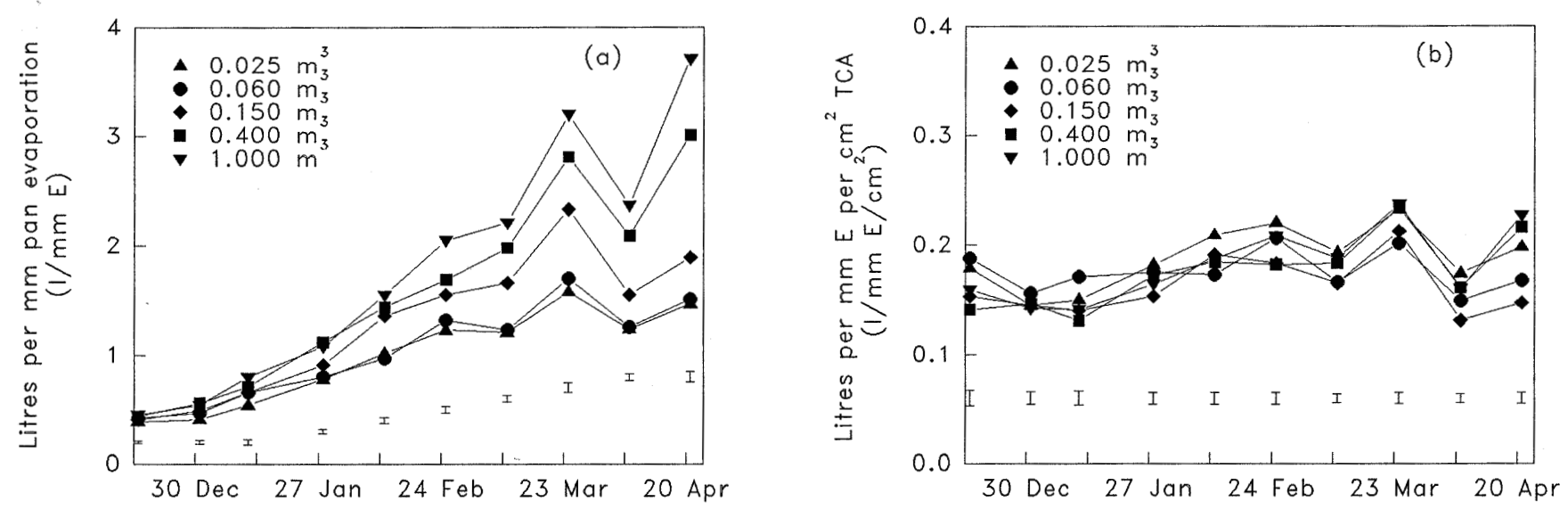

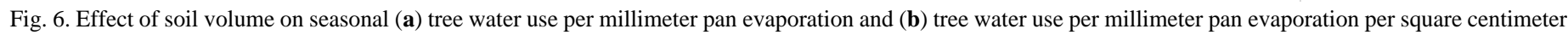
trunk cross-sectional area (TCA). Vertical bars are SEDS.

was not influenced. Rather, under nonlimited water supply, leaf area governed tree water use. Consequently, differences in water use over the season were attributed to tree size and, in terms of reproductive potential, water may have been wasted on larger volumes. Average tree water use per TCA over the season was 0.18 liters $/ \mathrm{mm} \mathrm{E}$ per $\mathrm{cm}^{2}$. This value compares with a water use of 0.22 liters $/ \mathrm{mm} \mathrm{E}$ per $\mathrm{cm}^{2}$ for trees grown in drainage lysimeters in their first year on an adjacent site (Mitchell et al., 1991).

In summary, in the first year of the experiment, trees in the small soil volumes made less vegetative growth without reducing leaf area per unit of canopy volume. They also used less water and had a similar reproductive potential to trees in the larger soil volumes. These results indicate that physically reducing available soil volume can reduce canopy volume, increase yield potential, and improve orchard management (trees being managed from the ground on the mini-Tatura trellis). Root restriction may be a practical approach to control tree size for tree fruit with no suitable dwarfing rootstocks. The optimum volume of soil restriction will be addressed in future seasons when fruit yield can be measured.

\section{Literature cited}

Black, J.D.F., P.D. Mitchell, and P.N. Newgreen. 1977. Optimum irrigation rates for young trickle irrigated peach trees. Austral. J. Expt. Agr. Animal Husbandry 17:342-345.

Boland, A.M., P.D. Mitchell, P.H. Jerie, and I. Goodwin. 1993. Effect of regulated deficit irrigation on tree water use and growth of peach. J. Hort. Sci. 68:261-274.

Chalmers, D.J. 1988. The role of root growth in regulation of assimilate partitioning and productivity of annual and perennial crops. Proc. 4th Intl. Congr. Microirr., Australia.

Chalmers, D.J., G. Burge, P.H. Jerie, and P.D. Mitchell. 1986. The mechanism of regulation of 'Bartlett' pear fruit and vegetative growth by irrigation withholding and regulated deficit irrigation. J. Amer. Soc. Hort. Sci. 111:904-907.

Chalmers, D.J., P.D. Mitchell, and L.A.G. van Heek. 1981. Control of peach tree growth and productivity by regulated water supply, tree density and summer pruning. J. Amer. Soc. Hort. Sci. 106:307-312.

Cockcroft, B. and J.C. Wallbrink. 1966a. Root distribution of orchard trees. Austral. J. Agr. Res. 17:49-54.

Cockroft, B. and J.C. Wallbrink. 1966b. Soil properties and tree vigor in the Goulburn Valley. Austral. J. Expt. Agr. Animal Husbandry 6:204-208.

Garnier, E. and A. Berger. 1985. Testing water potential in peach trees as an indicator of water stress. J. Hort. Sci. 60:47-56.

Jerie, P.H., B. van den Ende, and I. Dann. 1989. Managing tree vigor and fruitfulness in deciduous orchards. Acta Hort. 240:127-134.

Kramer, P.J. 1974. Fifty years of progress in water relations research. Plant Physiol. 54:463-471.

Lawes Agricultural Trust. 1990. Genstat 5. Rothamstead Expt. Sta., England.

Mitchell, P.D., A.M. Boland, J.L. Irvine, and P.H. Jerie. 1991. Growth and water use of young, closely planted peach trees. Scientia Hort. 47:283-293.

Mitchell, P.D. and D.J. Chalmers. 1982. The effect of reduced water supply on peach tree growth and yield. J. Amer. Soc. Hort. Sci. 107:853-856.

Mitchell, P.D., D.J. Chalmers, P.H. Jerie, and G. Burge. 1986. The use of initial withholding of irrigation and tree spacing to enhance the effect of regulated deficit irrigation on pear trees. J. Amer. Soc. Hort. Sci. 111:858-861.

Mitchell, P.D., P.H. Jerie, and D.J. Chalmers. 1984. The effects of regulated water deficits on pear tree growth, flowering, fruit growth and yield. J. Amer. Soc. Hort. Sci. 109:604-606.

Mitchell, P.D., B. van den Ende, P.H. Jerie, and D.J. Chalmers. 1989. Responses of 'Bartlett' pear to withholding irrigation, regulated deficit irrigation, and tree spacing. J. Amer. Soc. Hort. Sci. 114:15-19.

Proebsting, E.L. 1990. Controlled irrigation can affect fruit tree vigor. Good Fruit Grower (February).

Proebsting, E.L., P.H. Jerie, and J.L. Irvine. 1989. Water deficits and rooting volume modify peach tree growth and water relations. J. Amer. Soc. Hort. Sci. 114:368-372.

Purohit, A.G. 1989. High density planting of fruit tree-A review. II. Control of vegetative growth and tree size and deciding critical space. J. Maharashtra Agr. Univ. 14:133-36.

Richards, D. 1977. Root-shoot interactions: A functional equilibrium for water uptake in peach Prunus persica (L.) Batsch. Ann. Bot. 41:279-281.

Richards, D. 1981. Root-shoot interactions in fruiting tomato plants, p. 373-80. In: B. Brouwer, R. Brouer, O. Gasparikova, J. Kolek, B.C. Loughman (eds.) Structure and function of plant roots. Junk, The Hague.

Richards, D. 1986. Tree growth and productivity-The role of roots. Acta Hort. 175:27-36.

Richards, D. and B. Cockcroft. 1974. Soil physical properties and root concentrations in an irrigated peach orchard. Austral. J. Expt. Agr. Animal Husbandry 14:103-107.

Richards, D. and B. Cockroft. 1975. The effect of soil water on root production of peach trees in summer. Austral. J. Agr. Res. 26:173-180.

Richards, D. and R.N. Rowe. 1977a. Root-shoot interactions in peach: The function of the root. Ann. Bot. 41:1211-1216.

Richards, D. and R.N. Rowe. 1977b. Effects of the root restriction, root pruning and 6-benzylamino-purine on the growth of peach seedlings. Ann. Bot. 41:729-740.

Skene, J.K.M. and T.J. Poutsma. 1962. Soils and land use in part of the Goulburn Valley, Victoria, Australia. Dept. Agr. Tech. Bul. no. 14.

van den Ende, B. and D.J. Chalmers. 1982. An evaluation of commercial experience with the Tatura Trellis for growing peaches. HortScience 17:218-220.

van den Ende, B., D.J. Chalmers, and P.H. Jerie. 1987. Latest developments in training and management of fruit crops on Tatura Trellis. HortScience 22:561568.

Westwood, M.N. and A.N. Roberts. 1970. The relationship between trunk cross sectional area and weight of apple trees. J. Amer. Soc. Hort. Sci. 95:28-30.

Williamson, J.G. and D.C. Coston. 1990. Planting method and irrigation rate influence vegetative and reproductive growth of peach planted at high density. $\mathrm{J}$. Amer. Soc. Hort. Sci. 115:207-212.

Williamson, J.G., D.C. Coston, and J.A. Cornell. 1992. Root restriction affects shoot development of peach in a high-density orchard. J. Amer. Soc. Hort. Sci. 117:362-367. 